\title{
Plastic Food Packaging: Perceptions and Attitudes of Portuguese Consumers about Environmental Impact and Recycling
}

\author{
Morgana Weber Macena ${ }^{1}$ (D), Rita Carvalho ${ }^{2}$, Luísa Paula Cruz-Lopes ${ }^{1,3}$ and Raquel P. F. Guiné ${ }^{2,3, *(D)}$ \\ 1 School of Technology and Management, Polytechnic Institute of Viseu, 3504-510 Viseu, Portugal; \\ morganaweber.m@gmail.com (M.W.M.); lvalente@estgv.ipv.pt (L.P.C.-L.) \\ 2 Agrarian School, Polytechnic Institute of Viseu, 3500-606 Viseu, Portugal; anaamaral_26@hotmail.com \\ 3 CERNAS Research Centre, Polytechnic Institute of Viseu, 3504-510 Viseu, Portugal \\ * Correspondence: raquelguine@esav.ipv.pt
}

check for updates

Citation: Weber Macena, M.; Carvalho, R.; Cruz-Lopes, L.P.; Guiné, R.P.F. Plastic Food Packaging: Perceptions and Attitudes of Portuguese Consumers about Environmental Impact and Recycling Sustainability 2021, 13, 9953.

https://doi.org/10.3390/su13179953

Academic Editors: Graeme Moad and Tony Robert Walker

Received: 6 July 2021

Accepted: 30 August 2021

Published: 4 September 2021

Publisher's Note: MDPI stays neutral with regard to jurisdictional claims in published maps and institutional affiliations.

Copyright: (c) 2021 by the authors. Licensee MDPI, Basel, Switzerland. This article is an open access article distributed under the terms and conditions of the Creative Commons Attribution (CC BY) license (https:/ / creativecommons.org/licenses/by/ $4.0 /)$.

\begin{abstract}
The use of plastics for packaging has some advantages, since they are flexible and inexpensive. However, most plastics are of single use, which, combined with low recycling or reuse ratios, contributes substantially to environmental pollution. This work is part of a project studying the habits of Portuguese citizens concerning plastic food packaging and focuses on aspects related to sustainability. The survey was carried out via an online questionnaire about sustainability, recycling, and knowledge of the effects of plastic materials or their residues on the environment. The results were obtained based on a statistical analysis of the data. The participants tend to think about the negative impact of plastic packages on the environment; 39\% sometimes do not buy plastic; and 30\% try to look for alternatives. A substantial fraction, $81 \%$, support the avoidance of plastic utensils and reduction in the use of plastic bags. Most participants have a good knowledge of recycling and strongly agree with the use of recycled materials, and $87 \%$ of respondents practice separation of different types of waste for recycling. Changing plastic consumption habits has not been an easy task. Nevertheless, it is expected that society will increasingly move toward sustainable habits, questioning its actions and considering their impact on the environment.
\end{abstract}

Keywords: food packaging; plastic; recycling; knowledge; impact; questionnaire survey

\section{Introduction}

Food packaging is absolutely essential and modern food systems could not function properly without packaging. Todays' food chains are characterized by their vast geographical spread as well as by value chains at the global level [1]. The primary function of food packaging is to protect the product it contains, preserving its safety and organoleptic characteristics. Among these, properties such as flavour, colour and aroma are highly important for the consumer who will purchase and consume the product. Additionally, the package serves as a barrier for microorganisms and undesirable changes in temperature, light, and moisture, protecting the product during transport and storage against microbial spoilage, chemical modifications, or physical changes. [2]. The packaging functions required for a food package system are expressed as PC3, which stands for Protection, Containment, Communication and Convenience [3]. However, selecting an appropriate package is not the only factor that guarantees the product's shelf-life. In fact, besides selecting the proper material for packaging, which is crucial, the conditions under which the food is stored are equally important [4]. The package is the face of a product and is often the only experience consumers have before making a purchase [5]. Thus, it is essential that the package presents good aesthetics [4] to convince the consumers to buy the product. In this way, packaging can drive sales in a competitive market, as packaging can be designed to enhance the image or differentiate one product from others [6]. In addition, packages 
bring essential information about the product, such as a list of ingredients, nutritional composition, preparation instructions, brand identification, and prices [5].

Materials that have been commonly used in food packaging embrace glass [7,8], metals [9,10], paper [11,12], plastics [5,13-15], wood [16,17], textile and cork [4]. Modern packaging can encompass more than one type of material to explore and combine the functional or aesthetic properties of each one [5]. The kind of packaging applied varies according to the product characteristics, the level of protection required, the intended shelf-life, the target market, the distribution and the sales circuit [4]. Packaging production translates into a globalized industry characterized by its internal diversity, while on the other hand, each of its sectors individually influences the market [18].

The use of plastic bags to carry groceries and goods goes back to the 1970s [19], but plastic materials have been increasingly used for food since then. In the latest decades, the relative share of plastic on food packaging systems has been way too high due to the many advantages associated with the use of plastics for food packaging: they are fluid and mouldable, offering considerable design flexibility; they are inexpensive and lightweight; and they have a wide range of physical and optical properties [5]. However, they also have disadvantages, the most important ones being their permeability to light, gases, vapours, and low-weight molecules [5]. Plastics can be divided into two groups: thermoplastics and thermosets. Thermoplastics do not suffer chemical changes in their production so that they can be recycled. Contrarily, thermosets suffer chemical changes in their production, which preclude a new merge; therefore, they are not recyclable [2].

Most plastics are produced from petroleum and are discarded in the environment where they are not degradable, creating considerable environmental problems. The incorrect disposal of plastic bags, and other forms of plastics, has created a problem, since they have found a way to be everywhere, including the oceans, posing a threat to aquatic life, agricultural lands, and the environment in general [20]. Thus, alternatives to plastic bags are necessary, but these alternatives should be less harmful to the environment or have no impact at all [19]. The majority of plastics are of single-use; thus, a significant proportion of this material is lost each year. The immense production, combined with low levels of recycling or reuse, and insufficient sustainable policies to support the circular plastic economy, result in a large contribution of waste to the environment. The United States Environmental Protection Agency (EPA) estimated that 14.5 million tons of plastic containers and packaging were generated in 2018, corresponding approximately to $5 \%$ of municipal solid waste generation (in this analysis, the "plastic packaging" as a category excluded single-service plates and cups, as well as trash bags, which are classified as nondurable goods). In 2019, plastic packaging generated around $54 \%$ of the global anthropogenic waste [21]. According to EPA, the recycling rate of PET bottles and jars was 29.1 percent in 2018 (910,000 tons).

There are two ways to reduce the primary production of packaging, reuse, and recycling. In the reuse, the product is returned and reused in its original form. Another way to reuse is replacement; that is, containers which allow refilling. Examples of reuse are beverage packaging, such as returnable glass bottles, plastic packaging for personal care products, and cleaning products that would enable the use of refills, as well as refillable water bottles. Recycling involves converting the materials, involving reprocessing into new products [5]. Thus, to make recycling economically viable, the materials need to have a market. Recycling effectiveness is linked to several factors, such as the correct disposal of the material, the type of material, and its conditions after use. Materials such as paper and cardboard, metals, and glass have a more consolidated recycling market, unlike plastics, which have, however, gained more attention recently.

Plastic is not biochemically inert; thus, it can interact with the human body and the environment, causing negative impacts [21]. However, investment in truly sustainable innovations is still scarce. Industries that opt for sustainable packaging generally turn to the use of recycled materials, not considering the production of packaging which uses sustainable raw materials with a low degradation time [2]. Reducing the amount of pack- 
aging in food products represents an opportunity, as well as a challenge, for the food and beverage industry, as the main concern is related to food safety. Thus, finding ways to reduce its quantity and subsequent waste is a very challenging task [22]. The requirements for packaging and articles which remain in contact with food are becoming systematically more strict [18], as they can affect the health of consumers and the environment. Nevertheless, the criteria for packaging to produce the lowest environmental impact are difficult to define [22].

Recycled metal and glass materials are considered safe for use in packaging that remain in contact with food, as the heat used to melt and form the material is sufficient to kill microorganisms and pyrolyze organic contaminants. However, in the case of plastics, reprocessing uses enough heat to destroy microorganisms, but it is not enough to pyrolyze all organic contaminants. Thus, post-consumer recycled plastics are hardly used for food packaging [5]. In general, the smaller the number of polymeric components and complexity of plastic packaging, the greater is the recycling value, due to the reduction of steps and technological resources applied in the process [23]. The profitability of the package recycling market shows its attractive aspects for business initiatives in the sector. Still, the success of recycling is directly related to cultural, political, and socioeconomic factors, such as the implementation of recycling companies, the existence of selective collection, and the continuous availability of recyclable waste, incentive programs for recycling projects, encouraging the sale of recycled products, as well as actions in the production-use-consumption chain of packaging [23]. Understanding the profile of people who buy plastic is vital for planning future plastic reduction interventions, legislation, and campaigns [24].

The role of consumers is of most importance in order to help decision-making bodies and governmental regulators to successfully implement measures in order to reduce the use of plastic, and particularly those of single use, which have a high impact on the environment, as well as on human health, as final elements of the possible contamination chains. The study by Adam et al. [25] explored consumer's attitudes towards the single-use plastics in Ghana considering their effect on marine pollution. They found that while some consumers avoid the consumption of single-use plastics, others consume them without any restrictions. Nevertheless, there was a third group that, although also conscientious about the implications of single-use plastics, still sometimes use them. A study conducted with Canadian consumers [26] revealed that practically all of the participants (around 94\%) felt motivated to reduce the consumption of foods packed using single-use plastic. In this study, the authors also said that environmental concerns were more critical than food safety from the point of view of consumers. On this point, it was an undeniable fact that the Covid-19 pandemic brought to light new challenges concerning food safety, and therefore the work by Kitz et al. investigated the consumer perception of food packaging with single-use plastics during the Covid-19 period. They found that the motivation to reduce plastics was not so strong as before the pandemic, but this decline was not so pronounced among women as it was among men.

Although there is vast information in the literature about the negative impact of plastics on human health, as well as for the environment at the global scale, the information about the consumer's perceptions and knowledge and to what extent this shapes their behaviour and food choices is scarcer. To the best of our knowledge, this has not yet been accomplished for Portuguese consumers. This work is part of a project studying plastic food packaging, including Portuguese citizens' practices, knowledge, and concerns, from different perspectives, namely the impact on human health and the environment. This particular work has focused on the aspects related to sustainability, including recycling practices and knowledge about the impact of plastics on the ecosystems on a global scale. 


\section{Materials and Methods}

\subsection{Research Questions}

Having in mind the aim of this study to investigate the practices of Portuguese consumers towards the use of plastics for food packaging and recycling practices, as well as the degree of knowledge about their impact on the environment, our main research questions were:

RQ1: How do Portuguese consumers perceive the impact of plastic food packaging, including their negative impact on the environment?

RQ2: What are consumers' attitudes towards minimising the harmful impacts of plastic, including practicing recycling?

RQ3: What is the degree of knowledge of Portuguese consumers concerning recycling?

RQ4: What is the influence of the sociodemographic characteristics of the Portuguese consumers on eco-responsible behaviour towards plastic packaging and knowledge about recycling?

These research questions were assessed though a questionnaire survey, using an appropriate instrument for data collection.

\subsection{Questionnaire Survey}

The survey was done by a questionnaire that was designed purposely for this project. The instrument included six sections with questions to collect data for different goals: (I) Sociodemographic variables; (II) buying habits; (III) opinions about packaging; (IV) impact of packages in health and the environment; (V) recycling of plastic products; (VI) Education about plastic and recycling; (VII) knowledge about recycling; (VI) knowledge about the effects of plastic on health and the environment. This manuscript addressed the questions related to sustainability, including attitudes and recycling practices, as well as knowledge about the effects of plastic materials or their residues (such as microplastics) on the environment.

The survey was applied on a convenience sample due to the recruitment facility and considered the disposition to participate. Although the use of convenience samples has some drawbacks, they are extremely useful for research with an exploratory nature $[27,28]$. The sample size calculation, although not being applied directly to convenience samples, is also a helpful indicator for this type of research. In this case, the indicative sample size was calculated considering a 95\% confidence interval, corresponding to a level of significance of $5 \%$ and a $\mathrm{z}$ score of 1.96 [29,30]. The Portuguese population in 2019 (the last year available) was 10.286 million people [31], of which about $80 \%$ are adults, aged 18 years old or over, and targeting half of the adult population. The sample should include 385 participants [32-34] in order to be representative.

The data collection took place by the internet platform Google Forms, and the invitation to participate in the survey was sent by email and social networks. The inclusion criteria were: • Portuguese citizens; • participants with 18 years or more, meaning they were old enough to legally self-authorize to take part in the survey; $\bullet$ access to the internet; - access to a computer or other device through which they could answer the questionnaire; - able to understand the questions and express their responses; and $\bullet$ a willingness to participate in the research voluntarily and anonymously.

Strict ethical principles were obeyed when formulating the questionnaire and collecting the data, according to international standards (Declaration of Helsinki). The questionnaire was approved by the Ethical Commission at the Polytechnic Institute of Viseu with reference 09/SUB/2021. To all participants it was guaranteed that the internet tool used for the questionnaire would not record any data from the participants, such as email, IP or other sensitive information. Each participant could only access the questionnaire after agreeing to participate and after expressing informed consent.

The number of participants in the study was 487 , exceeding the calculated indicative number of 385 previously referred to. 


\subsection{Data Analysis}

For exploratory analysis of the data, basic descriptive statistics were used. Additionally, to access the relations between some of the categorical variables under study, the crosstabs and the chi-square test were used. The values of the Cramer's V coefficient allowed analysing the strength of the relations between variables. This coefficient varies from 0 to 1 , and its meaning is as follows: $\mathrm{V} \approx 0.1$, the association is weak; $\mathrm{V} \approx 0.3$, the association is moderate; and $\mathrm{V} \approx 0.5$ or over, the association is strong [35].

To validate the results obtained for the mean values calculated, a comparison of means was done by the analysis of variance (ANOVA), with the Post-Hoc Tukey HSD (Honestly Significant Difference) test for identification of the differences between samples for variables with three or more groups. For variables with two groups, the T-test for independent samples was used.

The variable accounting for the level of knowledge about recycling was submitted to a tree classification analysis to assess the relative importance of the sociodemographic variables. The analysis followed the CRT (Classification and Regression Trees) algorithm with a cross-validation and a minimum change in improvement of 0.0001 , considering a limit of 5 levels and a minimum number of cases for parent or child nodes equal to 20 and 15 , respectively [36]. A level of significance of $5 \%$ was considered in all statistical analyses.

To test the influence of the sociodemographic variables on eco-responsible behaviour towards plastic package, chi-square tests were conducted, based on the following null and alternative hypothesis:

Null Hypothesis (H0). There are NO significant differences between groups regarding the measured variable (ex: avoid plastic utensils);

Alternative Hypothesis (H1). The differences between groups are significant.

Additionally, to test the influence of the sociodemographic variables on the perception of the negative impact of plastics, ANOVA tests were conducted, based on the following null and alternative hypothesis:

Null Hypothesis (H0). There are NO significant differences between groups regarding the perception of the negative impact of plastics;

Alternative Hypothesis (H1). The differences between groups are significant.

In all cases, $\mathrm{H} 0$ was accepted if the $p$-value of the test was higher than 0.05 , which was the level of significance established, while for values of $p$ under $0.05, \mathrm{H} 0$ was rejected and H1 was accepted.

\section{Results}

3.1. Sociodemographic Characterization of the Sample

Table 1 shows the sociodemographic characteristics of the sample at study. Most participants were female $(70.4 \%)$ and resided in the central region of Portugal (64.9\%). The participants' ages varied from 18 to 88 years old, the average age being equal to $37.7 \pm 14.4$ years. The variable age was categorized into young adults (aged between 18 and 30 years) corresponding to $41.1 \%$, middle-aged adults (between 31 and 50 years) accounting for $35.5 \%$ and senior adults (51 years or older) representing $23.4 \%$. The majority had completed university graduation $(69.8 \%)$ and were currently employed $(55.4 \%)$. 
Table 1. Sociodemographic characterization of the sample $(n=487)$.

\begin{tabular}{llcc}
\hline \multicolumn{1}{c}{ Variable } & \multicolumn{1}{c}{ Group } & $\mathbf{n}$ & \% \\
\hline \multirow{2}{*}{ Sex } & Female & 343 & 70.4 \\
& Male & 144 & 29.6 \\
\hline \multirow{2}{*}{ Residence } & North & 75 & 15.4 \\
& Centre & 316 & 64.9 \\
& South and Islands & 96 & 19.7 \\
\hline \multirow{2}{*}{ Age } & Young adults (18-30 years) & 200 & 41.1 \\
& Middle-aged adults (31-50 years) & 173 & 35.5 \\
& Senior adults ( $\geq 51$ years) & 114 & 23.4 \\
\hline \multirow{2}{*}{ Education level } & Up to secondary school or CET & 147 & 30.2 \\
& University Degree & 340 & 69.8 \\
\hline \multirow{2}{*}{ Professional status } & Employed & 270 & 55.4 \\
& Unemployed & 24 & 4.9 \\
& Student & 134 & 27.5 \\
& Retired & 21 & 4.3 \\
& Working-student & 38 & 7.8 \\
\hline
\end{tabular}

\subsection{Attitudes and Perceptions Regarding Plastic Food Packaging}

The majority of participants were responsible for buying the foods they consume $(\mathrm{n}=338)$, while some only buy their food sometimes $(\mathrm{n}=132)$. In the case of 17 participants, someone else buys their food.

At the moment of purchasing, participants tend to think about the negative impact of the plastic package on the environment, as seen in Figure 1. However, only 30\% try to look for alternatives.

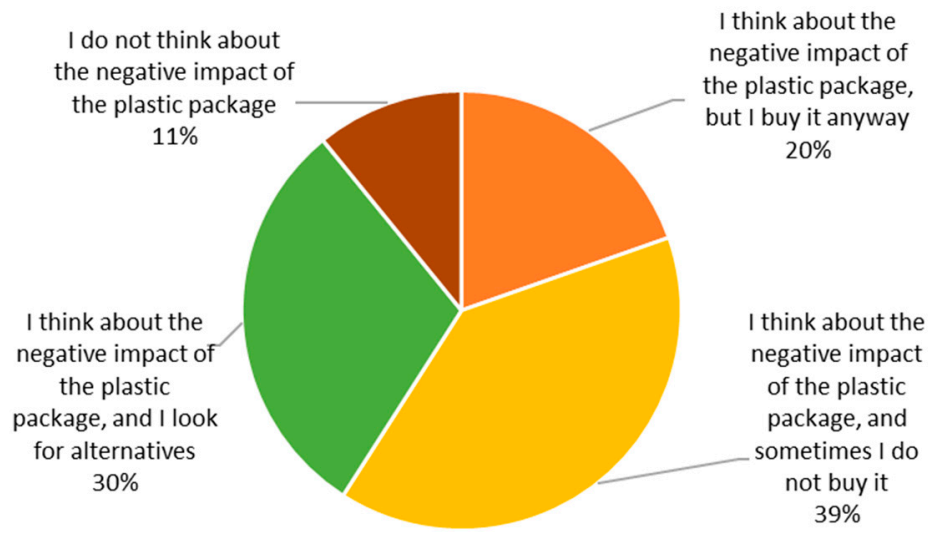

Figure 1. Thoughts regarding the impact of plastic food packaging at the moment of purchase.

The research also included a question aimed to evaluate how each participant classified on a scale from 1 (no impact) to 10 (maximum impact) concerning the negative impact of plastics on different elements of the environment, and the results are presented in Figure 2. In general, the participants classified the impacts into levels 7 to 10. The maximum impact (corresponding to score 10) was always the score that got the most answers, with particular relevance for the impact of plastics on the seas/oceans (attributed by 344 participants) followed by rivers $(n=298)$ and ecosystems $(n=292)$. The negative impact of plastics is a little less perceived on agricultural soils or forests than other elements of the environment. 
Scores of impact: $\square 1 \backsim 2 \backsim 3 \backsim 4 \backsim 5 \square 6 \square 7 \square 8 \square 9 \square 10$

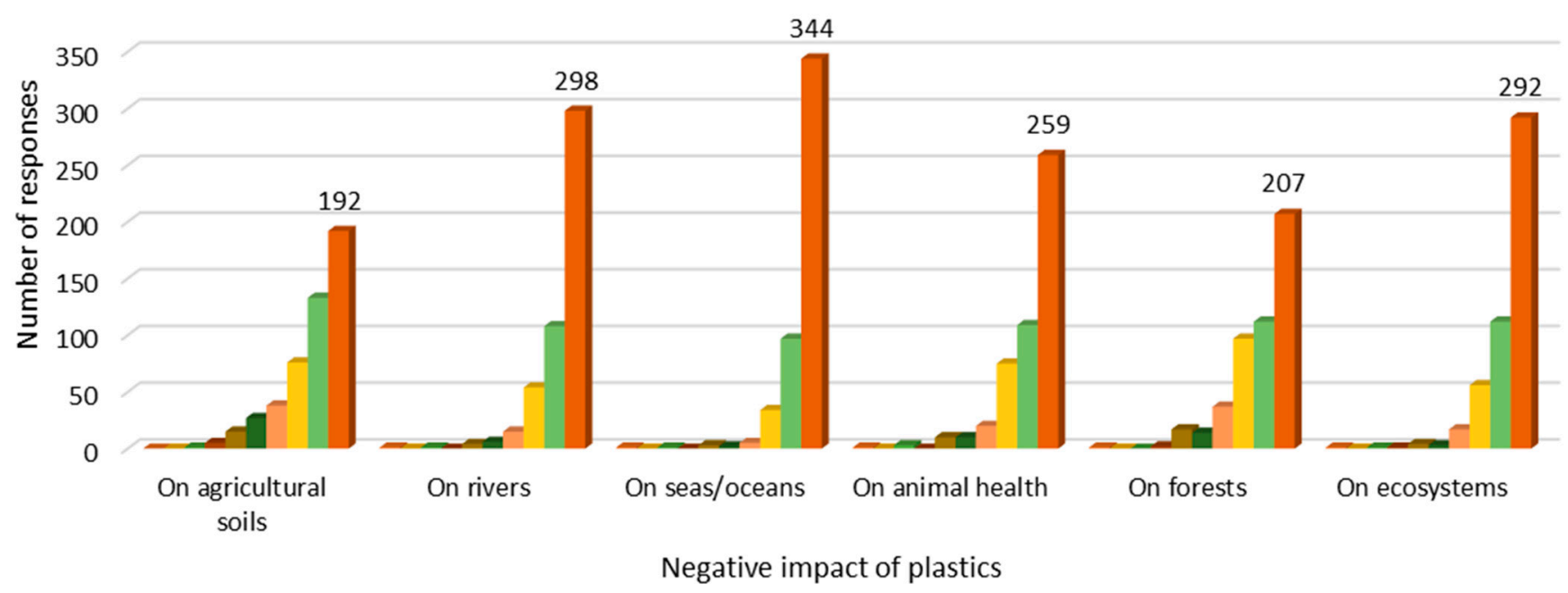

Figure 2. Perceived negative impact of plastics on the environment.

The scores given by the participants were used to calculate the indices that measure the perceived negative impact of plastic on the environment. These were calculated as the mean value and are, by decreasing order: impact on seas / oceans (9.55 \pm 0.93$)$, impact on rivers $(9.34 \pm 1.09)$, impact on ecosystems $(9.32 \pm 1.09)$, impact on animals $(9.10 \pm 1.09)$, impact on forests $(8.81 \pm 1.40)$ and impact on agricultural soils $(8.73 \pm 1.46)$, all measured in the scale from 1 (minimum impact) to 10 (maximum impact).

Table 2 presents some of the aspects investigated relating to the measures adopted by the participants to minimize the harmful impacts of plastic materials and their recycling. A very expressive majority of the participants separate the plastic residues for recycling $(87 \%)$, avoid plastic utensils and reduce the use of plastic bags (81\% for both options). However, when it comes to avoiding purchasing products with excessive plastic, only about half of the participants adopt this measure (55\%). The results in Table 2 also show that most participants recycle as a usual practice (74\%), and 59\% admit doing it always. Most participants have containers for recycling in their homes (81\%), and they are located essentially in the kitchen $(60 \%)$. In comparison, at the working place, less participants have recycling containers $(62 \%)$, and these are situated in the corridors $(31 \%)$ or in the bar $(29 \%)$. Public containers for recycling, particularly plastic, are usually present near the workplace $(52 \%)$ and the house $(87 \%)$ of the participants. On average, in a week, the participants deposit waste into public bins only once (for 55\% of the participants), and regarding the plastic residues, they produce one bag per week (50\%) or two to five bags (44\% of participants).

Table 2. Attitudes towards minimising the harmful impacts of plastic and recycling.

\begin{tabular}{lcc}
\hline Measures Adopted to Minimize the Harmful Impact of Plastics & $\mathbf{n}$ & $\mathbf{\%}$ \\
\hline Separate plastic residues for recycling & 422 & $87 \%$ \\
Avoid consume plastic utensils, such as dishes, straws, glasses, silverware & 393 & $81 \%$ \\
Reduce the use of plastic bags & 393 & $81 \%$ \\
Use cloth bags to transport foods and other goods & 299 & $61 \%$ \\
Avoid purchasing products with excessive plastic & 266 & $\mathbf{n}$ \\
\hline Recycling of Plastic Materials & $\mathbf{n}$ \\
\hline Do you usually recycle? & 362 & $74 \%$ \\
Yes & 30 & $6 \%$ \\
No & 95 & $20 \%$ \\
\hline
\end{tabular}


Table 2. Cont.

\begin{tabular}{|c|c|c|}
\hline Recycling of Plastic Materials & $\mathbf{n}$ & $\%$ \\
\hline \multicolumn{3}{|c|}{ Do you usually select and separate plastic food packages for recycling? } \\
\hline Never & 5 & $1 \%$ \\
\hline Sometimes & 54 & $12 \%$ \\
\hline Frequently & 128 & $28 \%$ \\
\hline Always & 270 & $59 \%$ \\
\hline \multicolumn{3}{|c|}{ In your house do you have containers for recycling? } \\
\hline Yes & 370 & $81 \%$ \\
\hline No & 87 & $19 \%$ \\
\hline \multicolumn{3}{|c|}{ Where are the containers, in your house? } \\
\hline In the kitchen & 294 & $60 \%$ \\
\hline In the attic & 1 & $0 \%$ \\
\hline In the basement & 7 & $1 \%$ \\
\hline In the garage & 30 & $6 \%$ \\
\hline Other & 65 & $13 \%$ \\
\hline \multicolumn{3}{|c|}{$\begin{array}{l}\text { On average, per week, how many times do you deposit residues in the public } \\
\text { waste bin? }\end{array}$} \\
\hline Once & 247 & $55 \%$ \\
\hline 2 times & 125 & $28 \%$ \\
\hline 3-4 times & 53 & $12 \%$ \\
\hline More than 4 times & 28 & $6 \%$ \\
\hline \multicolumn{3}{|c|}{ On average, per week, how many bags full of plastic residues do you produce? } \\
\hline One bag & 226 & $50 \%$ \\
\hline $2-5$ bags & 212 & $47 \%$ \\
\hline $6-10$ bags & 13 & $3 \%$ \\
\hline More than 10 bags & 3 & $1 \%$ \\
\hline \multicolumn{3}{|c|}{$\begin{array}{l}\text { In your area of residence, which type of public containers do you have to } \\
\text { deposit residues? }\end{array}$} \\
\hline Common waste & 452 & $93 \%$ \\
\hline Plastic & 425 & $87 \%$ \\
\hline Glass & 425 & $87 \%$ \\
\hline Paper & 422 & $87 \%$ \\
\hline Oil & 148 & $30 \%$ \\
\hline Batteries & 129 & $26 \%$ \\
\hline \multicolumn{3}{|c|}{ In your workplace do you have containers for recycling? } \\
\hline Yes & 282 & $62 \%$ \\
\hline No & 175 & $38 \%$ \\
\hline \multicolumn{3}{|c|}{ Where are the containers, in your workplace? } \\
\hline In the office & 60 & $12 \%$ \\
\hline In the meeting rooms & 15 & $3 \%$ \\
\hline In the bar & 139 & $29 \%$ \\
\hline In the copies room & 32 & $7 \%$ \\
\hline In the corridors & 150 & $31 \%$ \\
\hline Others & 124 & $25 \%$ \\
\hline \multicolumn{3}{|c|}{$\begin{array}{l}\text { In your area of work which type of public containers do you have to deposit } \\
\text { residues? }\end{array}$} \\
\hline Common waste & 377 & $77 \%$ \\
\hline Plastic & 252 & $52 \%$ \\
\hline Glass & 192 & $39 \%$ \\
\hline Paper & 282 & $58 \%$ \\
\hline Oil & 37 & $8 \%$ \\
\hline Batteries & 82 & $17 \%$ \\
\hline
\end{tabular}




\subsection{Information and Knowledge about Recycling}

Practically, all participants $(n=478)$ refer that they believe school should have a more important role in the awareness about the harmful effects of plastics as well as about the recycling practices. They also believe that some aspects should be addressed at schools, like those which were presented to the respondents:

- $\quad$ Right attitudes about recycling food packaging (selected by 455 participants)

- Behaviours to have when using food packaging $(n=448)$

- $\quad$ Packaging constituents and their decomposition $(n=405)$

- Forms of degradation of plastic packaging in soil and water $(n=431)$

- Risks to public health due to inappropriate recycling practices $(n=466)$

Other topics also referred to by some participants on open question include: sustainable alternatives to the use of plastic; the various options available on the market regarding plastic replacements; schools setting examples; the problem of micro- and nano-plastics and their influence on human health and ecosystems; citizenship and responsibility in eco-sustainability; the principle of respect for ourselves and others; the awareness of the importance of reduction and recovery, rather than encouraging recycling; circular economy and in particular of plastic packaging; ways to replace plastic in the consumer society and what this transition would represent, opportunities and challenges, global impact on all ecosystems, on planet earth and future generations; the importance of avoiding endocrine disrupting plastics like bisphenol A (BPA); plastic particles, for example, released when the package is heated, and which can contaminate food.

Moreover, $99 \%$ of the participants $(n=481)$ agree that schools should have a more critical role in teaching about the sustainability of natural resources. They believe that the most appropriate means to receive information/alerts on good recycling practices are social media (405 participants agree on this) followed by email $(n=252)$ or text messages on the mobile phone $(n=191)$.

The frequency with which the participants obtain information about recycling through several ways is indicated in Figure 3. The results reveal that only the internet is referred to as a frequent source of information for a relevant percentage of participants (about $30 \%$ ). In contrast, the other forms of obtaining information are used only sporadically or sometimes.

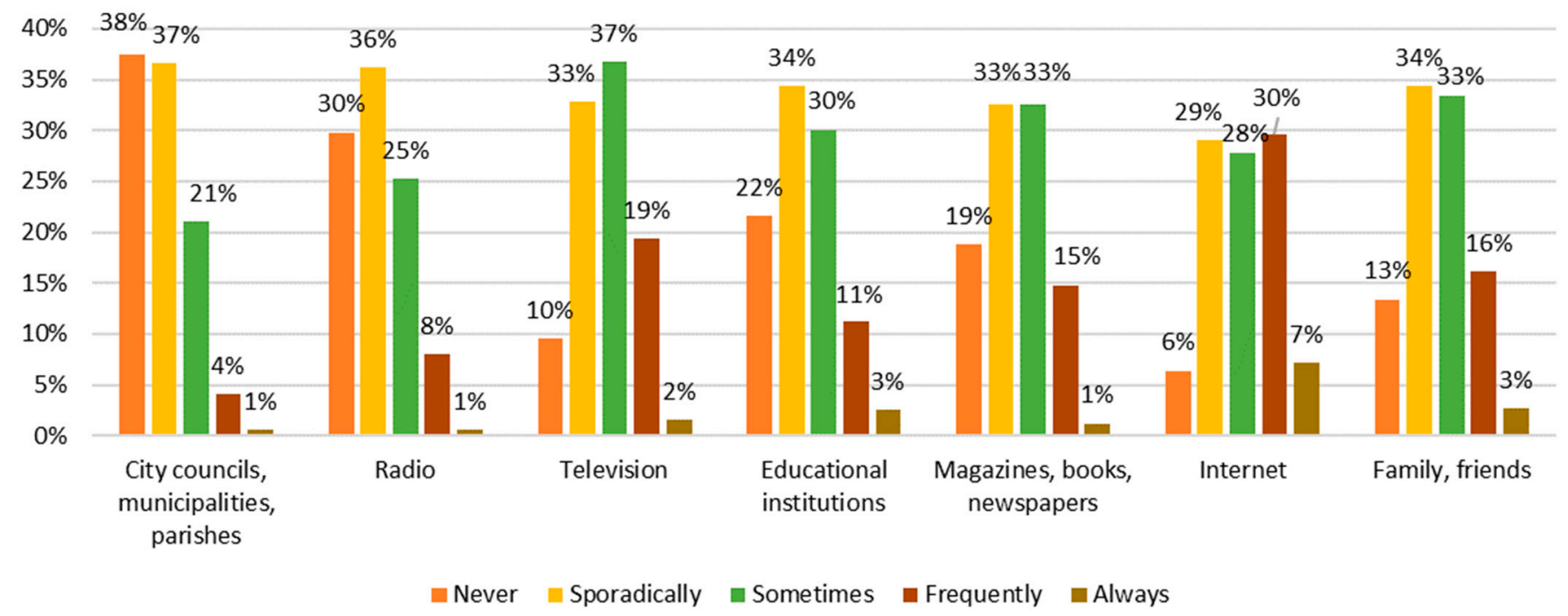

Figure 3. Frequency of obtaining information about recycling.

The knowledge about some facts related to recycling and plastics was assessed through a number of statements and the participants were asked to indicate their level of agreement on a five-point Likert scale from totally disagree (1) to totally agree (5) (Table 3). Most participants agreed $(40.9 \%)$ or totally agreed $(40.9 \%)$ with item 1 , about the use of recycled materials. Regarding the fact that recycling of packaging materials originates new raw 
materials (item 2) $45.6 \%$ agreed, and $22.2 \%$ totally agreed with it. Similar percentages were obtained for item 3 , which refers to the operations that plastic undergoes when being recycled. The lower impact of glass over plastic was also acknowledged by many participants (40.2\% agree and $27.1 \%$ totally agree). Item 7 was a false statement included to evaluate if the participants could distinguish this false fact, and, although there were still many participants revealing an incorrect agreement with the item, nearly $30 \%$ totally disagreed and about $13 \%$ disagreed, which indicates that nearly half of the participants had a proper knowledge of the fact that not all glass materials are placed into the green recycling bin. The last two items were more difficult for the participants to express an opinion, as high percentages of participants did not express an opinion $(56.3 \%$ and $61.6 \%$, respectively, replied neither agree nor disagree).

Table 3. Knowledge about recycling.

\begin{tabular}{|c|c|c|c|c|c|}
\hline Items & $\begin{array}{l}\text { Totally } \\
\text { Disagree } \\
\quad(1)\end{array}$ & $\begin{array}{l}\text { Disagree } \\
\text { (2) }\end{array}$ & $\begin{array}{l}\text { Neither } \\
\text { Agree Nor } \\
\text { Disagree } \\
\text { (3) }\end{array}$ & $\begin{array}{l}\text { Agree } \\
(4)\end{array}$ & $\begin{array}{l}\text { Totally } \\
\text { Agree } \\
\mathbf{( 5 )}\end{array}$ \\
\hline $\begin{array}{l}\text { 1. It is better for the environment to buy products } \\
\text { with packaging made from recycled materials }\end{array}$ & $1.0 \%$ & $2.3 \%$ & $15.0 \%$ & $40.9 \%$ & $40.9 \%$ \\
\hline $\begin{array}{l}\text { 2. If all plastic packaging is recycled, we will have } \\
\text { new raw materials again }\end{array}$ & $2.1 \%$ & $11.9 \%$ & $18.3 \%$ & $45.6 \%$ & $22.2 \%$ \\
\hline $\begin{array}{l}\text { 3. When plastic arrives at the sorting stations, it is } \\
\text { washed, crushed and processed, transforming } \\
\text { itself, and giving rise to urban furniture, clothing, } \\
\text { tubes, vases, etc ... }\end{array}$ & $1.4 \%$ & $5.1 \%$ & $21.8 \%$ & $47.2 \%$ & $24.4 \%$ \\
\hline $\begin{array}{l}\text { 4. When going to the supermarket and the same } \\
\text { product is available in glass and plastic packaging, } \\
\text { it is better to choose the glass one in view of the } \\
\text { comparative impact of these materials }\end{array}$ & $3.9 \%$ & $8.6 \%$ & $20.1 \%$ & $40.2 \%$ & $27.1 \%$ \\
\hline $\begin{array}{l}\text { 5. Broken dishes and glasses must be placed in the } \\
\text { green recycling bin (false statement) }\end{array}$ & $29.8 \%$ & $12.9 \%$ & $12.9 \%$ & $23.2 \%$ & $21.1 \%$ \\
\hline 6. Portugal in 2019 met the plastic recycling target & $11.1 \%$ & $18.9 \%$ & $56.3 \%$ & $9.9 \%$ & $3.9 \%$ \\
\hline $\begin{array}{l}\text { 7. In just over two decades, Portugal has separated } \\
\text { and sent for recycling more than } 7 \text { million tons of } \\
\text { packaging waste }\end{array}$ & $3.7 \%$ & $5.1 \%$ & $61.6 \%$ & $23.0 \%$ & $6.6 \%$ \\
\hline
\end{tabular}

\subsection{Influence of Sociodemographic Factors on Eco-Responsible Behaviour towards Plastic Package}

Table 4 presents the cross-tabulation between the sociodemographic variables measuring the attitudes of the participants regarding plastic packages. Concerning the question of whether the participants think about the impact of the plastic package in the moment of purchase, significant differences were found between groups for sex and education ( $p$-value of 0.013 and 0.010 , respectively). Still, the associations were weak in both cases $(V=0.152$ and $V=0.156)$. The participants who tried to adapt their purchases more according to the minimization of the negative impacts of plastic were women with an under-university level of education.

Concerning the separation of residues for recycling, significant differences were found between groups for age and profession ( $p$-value $<0.0005$ in both cases), with moderate associations $(V=0.263$ and $V=0.241)$. The separation of residues increased as age increased, and those who recycled more were retired (100\%) or employed $(92.6 \%)$. 
Table 4. Association between sociodemographic variables and attitudes towards sustainability of plastics.

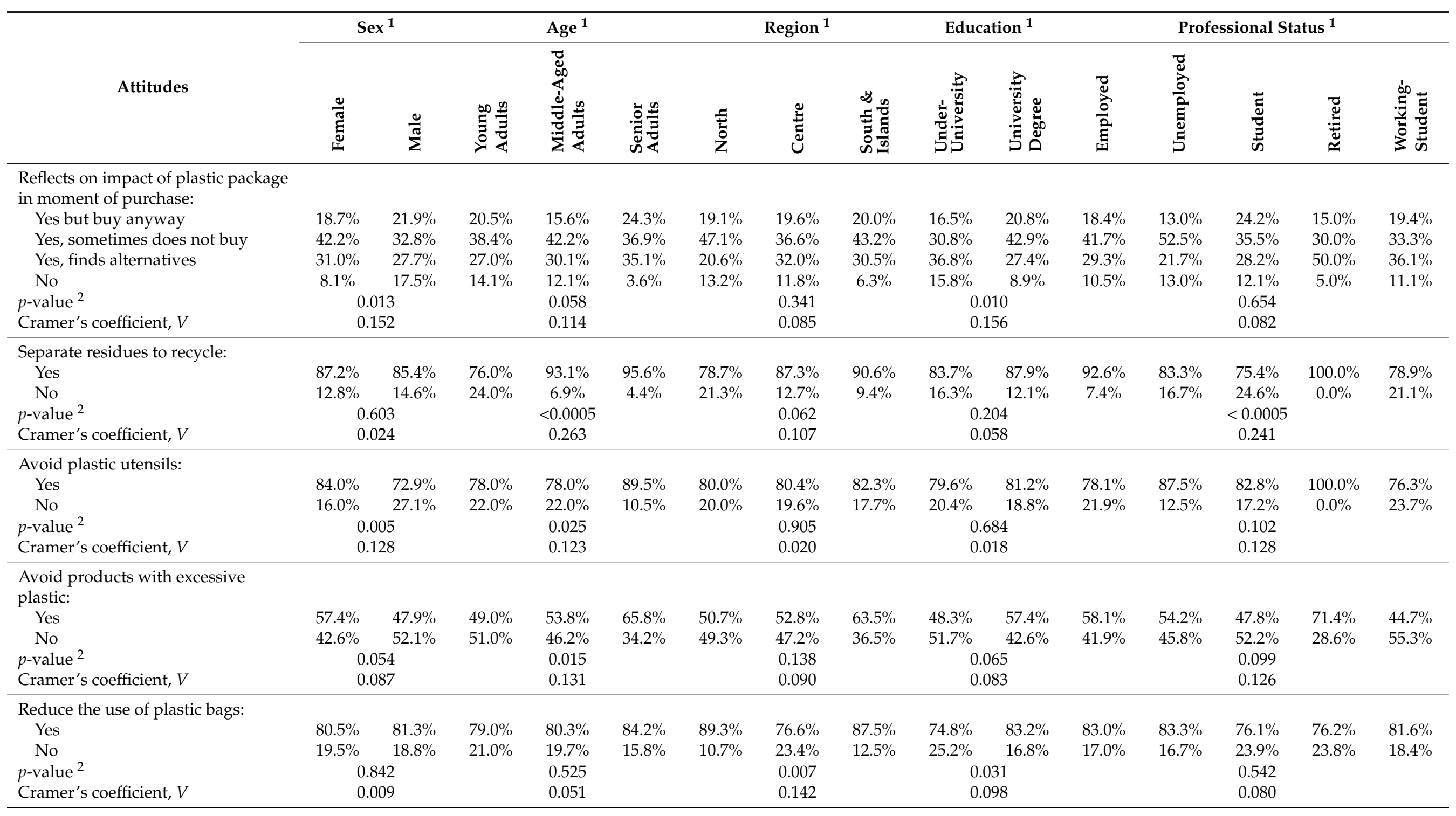


Table 4. Cont.

\begin{tabular}{|c|c|c|c|c|c|c|c|c|c|c|c|c|c|c|c|}
\hline \multirow{2}{*}{ Attitudes } & \multicolumn{2}{|c|}{$\operatorname{Sex}^{1}$} & \multicolumn{3}{|c|}{ Age $^{1}$} & \multicolumn{3}{|c|}{ Region ${ }^{1}$} & \multicolumn{2}{|c|}{ Education $^{1}$} & \multicolumn{5}{|c|}{ Professional Status $^{1}$} \\
\hline & 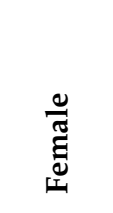 & $\sum^{\frac{0}{\pi}}$ & 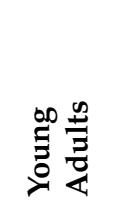 & 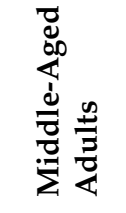 & 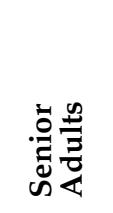 & $\begin{array}{l}\mathbf{E} \\
\dot{Z} \\
\mathbf{Z}\end{array}$ & 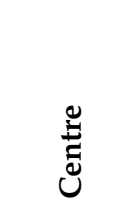 & 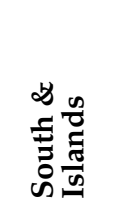 & 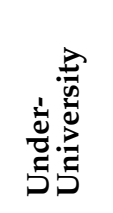 & 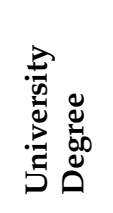 & 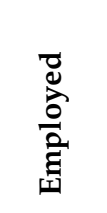 & 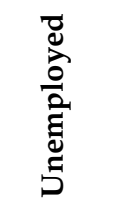 & 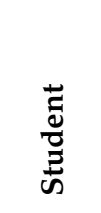 & $\begin{array}{l}\overparen{D} \\
\simeq \\
\simeq\end{array}$ & 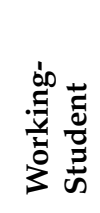 \\
\hline \multicolumn{16}{|c|}{$\begin{array}{l}\text { Use cloth bags to transport foods } \\
\text { and other goods: }\end{array}$} \\
\hline No & $36.2 \%$ & $44.4 \%$ & $36.0 \%$ & $38.2 \%$ & $43.9 \%$ & $42.7 \%$ & $40.5 \%$ & $29.2 \%$ & $36.1 \%$ & $39.7 \%$ & $41.9 \%$ & $58.3 \%$ & $32.1 \%$ & $28.6 \%$ & $31.6 \%$ \\
\hline$p$-value ${ }^{2}$ & \multicolumn{2}{|c|}{0.086} & \multicolumn{3}{|c|}{0.384} & \multicolumn{3}{|c|}{0.100} & \multicolumn{2}{|c|}{0.447} & \multicolumn{5}{|c|}{0.056} \\
\hline Cramer's coefficient, $V$ & \multicolumn{2}{|c|}{0.078} & \multicolumn{3}{|c|}{0.063} & \multicolumn{3}{|c|}{0.097} & \multicolumn{2}{|c|}{0.034} & \multicolumn{5}{|c|}{0.138} \\
\hline \multicolumn{16}{|c|}{$\begin{array}{l}\text { Frequency of separation of plastic for } \\
\text { recycling: }\end{array}$} \\
\hline Never & $1.2 \%$ & $0.8 \%$ & $0.6 \%$ & $2.4 \%$ & $0.0 \%$ & $1.5 \%$ & $1.3 \%$ & $0.0 \%$ & $0.0 \%$ & $1.6 \%$ & $1.5 \%$ & $0.0 \%$ & $0.8 \%$ & $0.0 \%$ & $0.0 \%$ \\
\hline Sometimes & $12.3 \%$ & $10.5 \%$ & $20.2 \%$ & $6.6 \%$ & $6.3 \%$ & $23.5 \%$ & $11.7 \%$ & $3.3 \%$ & $17.6 \%$ & $9.3 \%$ & $8.0 \%$ & $17.4 \%$ & $21.0 \%$ & $4.8 \%$ & $9.1 \%$ \\
\hline Frequently & $25.9 \%$ & $33.1 \%$ & $30.9 \%$ & $29.3 \%$ & $21.4 \%$ & $19.1 \%$ & $29.4 \%$ & $30.0 \%$ & $35.3 \%$ & $24.9 \%$ & $27.6 \%$ & $34.8 \%$ & $29.4 \%$ & $19.0 \%$ & $27.3 \%$ \\
\hline Cramer's coefficient, $V$ & \multicolumn{2}{|c|}{0.075} & \multicolumn{3}{|c|}{0.184} & \multicolumn{3}{|c|}{0.140} & \multicolumn{2}{|c|}{0.188} & \multicolumn{5}{|c|}{0.121} \\
\hline
\end{tabular}

${ }^{1}$ Percentages in Column. ${ }^{2}$ Chi-square test $p$-value at a level of significance of $5 \%$. 
The avoidance of plastic utensils is stronger for women and for senior adults, with significant differences between groups ( $p=0.005$ and $p=0.025$, respectively). However, the associations in both cases are weak $(V=0.128$ and $V=0.123$, respectively). Regarding avoidance of products with excessive plastic, only significant differences were found for groups of age $(p=0.015)$, with a higher avoidance rate for increasing age, although this association is weak $(V=0.131)$.

Reducing the use of plastic bags is less prevalent for participants from the central region of Portugal, with significant differences and a low association $(p=0.007$ and $V=0.142)$, while it is significantly more prevalent in people with a university degree $(p=0.031$ and $V=0.098$ ). On the other hand, no significant differences were found for any of the sociodemographic variables studied for the use of cloth bags to transport foods and other goods.

Finally, concerning the frequency of separation of plastic for recycling, significant differences were found between groups of age, region and education level $(p<0.0005$, $p=0.006$ and $p=0.001$, respectively), but the associations were weak in all cases $(V=0.184$, $V=0.140$ and $V=0.188)$.

3.5. Influence of Sociodemographic and Behevioural Factors on Perceptions of the Impact of Plastics and Knowledge about Recycling

For each participant, the six variables accounting for the negative impact of plastics (soils, rivers, oceans, animals, forest, ecosystems) were used to calculate an average perception of the negative impact of plastics on the environment and possible significant differences between groups of sociodemographic variables were tested as shown in Table 5 . Only for sex was there found significant differences $(p=0.018)$, with women revealing a higher level of perception about the negative impact of plastics $(9.21 \pm 1.00)$ as compared with men $(8.97 \pm 1.10)$.

Table 5. Perception of the negative impact of plastics according to sociodemographic groups.

\begin{tabular}{|c|c|c|}
\hline Variable & Group & $\begin{array}{l}\text { Perception of the Negative Impact of } \\
\text { Plastics on the Environment }{ }^{1}\end{array}$ \\
\hline \multirow[t]{3}{*}{ Sex } & Female & $9.21 \pm 1.00$ \\
\hline & Male & $8.97 \pm 1.10$ \\
\hline & $p$-value ${ }^{2}$ & 0.018 \\
\hline \multirow[t]{4}{*}{ Age } & Young adults & $9.25 \pm 0.88^{a}$ \\
\hline & Middle-aged adults & $9.03 \pm 1.01^{\mathrm{a}}$ \\
\hline & Senior adults & $9.10 \pm 1.28^{a}$ \\
\hline & $p$-value ${ }^{3}$ & 0.137 \\
\hline \multirow[t]{4}{*}{ Residence } & North & $9.18 \pm 0.97^{a}$ \\
\hline & Centre & $9.20 \pm 1.03^{a}$ \\
\hline & South \& Islands & $8.91 \pm 1.07^{\mathrm{a}}$ \\
\hline & $p$-value ${ }^{3}$ & 0.093 \\
\hline \multirow[t]{3}{*}{ Education level } & Under-university & $9.26 \pm 1.08$ \\
\hline & University Degree & $9.09 \pm 1.01$ \\
\hline & $p$-value ${ }^{2}$ & 0.088 \\
\hline \multirow[t]{6}{*}{ Professional status } & Employed & $9.09 \pm 1.12^{\mathrm{a}}$ \\
\hline & Unemployed & $8.57 \pm 1.09^{a}$ \\
\hline & Student & $9.26 \pm 0.90^{\mathrm{a}}$ \\
\hline & Retired & $9.18 \pm 0.77^{a}$ \\
\hline & Working-student & $9.14 \pm 0.99^{a}$ \\
\hline & $p$-value ${ }^{3}$ & 0.866 \\
\hline Global sample & & $9.14 \pm 1.03$ \\
\hline
\end{tabular}

${ }^{1}$ Mean value \pm standard deviation (scale from 1-minimum impact to 10 -maximum impact). ${ }^{2}$ T-test for independent samples, level of significance of $5 \% .{ }^{3}$ ANOVA with Post-Hoc Tukey test, level of significance of $5 \%$. Values with the same letter are not significantly different. 
The seven items used to measure knowledge about recycling were used, after reversing the negative item (number 5), to assess an average level of knowledge for each participant, computed as the mean value, varying in the scale from -2 to +2 . These values were then categorized into: very low knowledge-mean $\in[-2 ;-1[$, low knowledge-mean $\in[-1 ; 0$ [, high knowledge-mean $\in[0 ; 1$ [ and very high knowledge-mean $\in[1 ; 2]$, and this variable was used for the tree classification considering the sociodemographic variables studied, as shown in Figure 4. The obtained tree is five levels deep, with 21 nodes, from which 11 are terminal. The risk estimates were 0.267 for resubstitution and cross-validation, with standard errors of 0.020 in both cases. According to the results obtained, the first discriminant variable was profession, separating people employed from those with other job situations. Among the employed, the percentage of participants with a very high knowledge was higher $(23.3 \%)$ than for other groups. For the employed, the next discriminant was residence, with those living in the North showing more people with a very high level of knowledge. For participants living in the centre and the South and Islands, the following discriminant variable was age, and for the next level, age separated again the young adults from the middle-aged adults (lower percentage of very high knowledge, $24.2 \%$ ). Sex was the final discriminant for this group, for which women showed a higher percentage in the category of very high knowledge (26.6\%).

For participants with other professional status than the employed, age was the second discriminating variable, separating young adults for which the percentage of very high knowledge was lower $(10.2 \%)$ from the middle aged or senior adults. The discriminating variable for the next level in these two groups was education, and for the young adults with a level of education under university, the last discriminant was sex, with women showing a higher percentage for very high knowledge $(9.1 \%)$. 


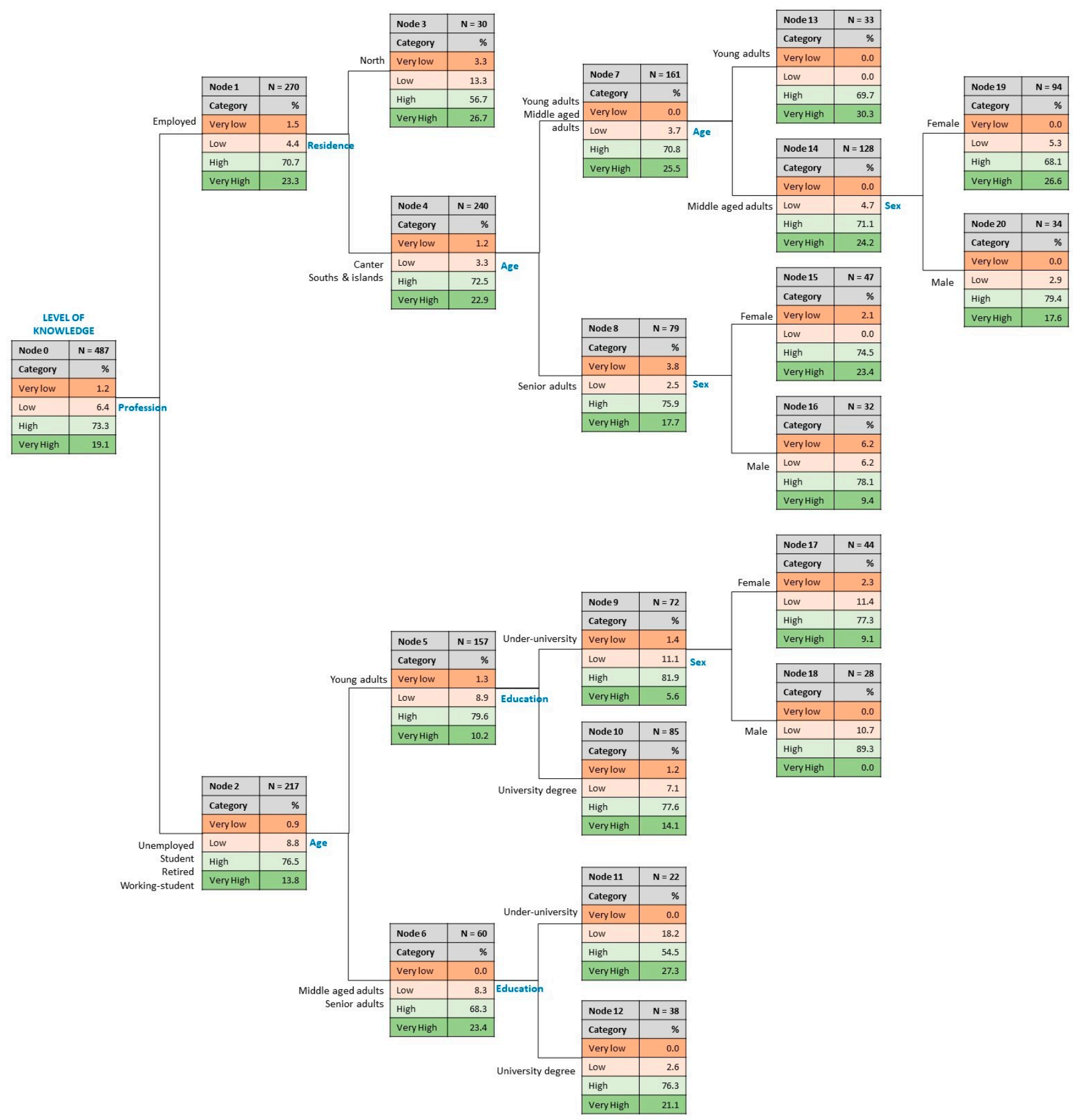

Figure 4. Tree classification for variable level of knowledge about recycling.

\section{Discussion}

Understanding the different perceptions of the public can allow government authorities to make informed decisions about funding and management priorities, promoting cooperation between society, institutions, and governments [37]. Therefore, knowing the consumers' awareness about the use of plastics and their effects on human health and for the environment can be a trigger for governmental authorities, as well as for industries, to actively promote the shift towards more sustainable packaging systems. Plastics are a part of many items present in our daily lives in many sectors, but packaging is one of the areas that highly contribute to the use of plastics, and in many cases single-use plastics. The increase in the use of plastic in various sectors has caused concern regarding the usage 
of natural resources for its production, the toxicity associated with its manufacture and use, and the environmental impacts generated by its disposal [20]. To positively contribute to sustainability, packages should be made from environmentally adequate sources, applying clean production technologies with the possibility of being recovered or recycled after being used. Sustainability also depends on consumers, and if the product is not correctly discharged, the sustainability is compromised [2].

The recycling of plastic packaging worries society due to the growing use of these materials and the environmental implications inherent to their non-rational post-consumer disposal [23]. In this work, it was observed that this concern is present since the great majority of participants practice recycling. A similar result was found by Forleo and Romagnoli [38] in Italy, with $87 \%$ of respondents always following the separate disposal of plastics. Several factors may have an impact on waste disposal and recycling [5]. Among these stand, for example, the presence of other materials (combined packaging), labels, dirt, damage, or food residues, which remain in post-consumer packaging [23]. Moreover, the economic feasibility of recycling, including the costs of collecting, separating, cleaning or reprocessing and transporting waste [5], highly influences the recycling of plastic materials. In this study, most participants agreed or totally agreed with the use of recycled materials, and demonstrated a good knowledge about recycling, and the higher negative impact of plastics over glass. Plastic is known as the most difficult household waste to degrade. Its degradation releases toxic residues that pollute soil, air, and water [39]. However, people are aware of the negative impact of plastic waste on the environment, and this study confirmed it, with the oceans/seas as the natural sites of greatest concern.

Problems related to its use in food packaging often result from the release of nonplastic components. When exposed to high temperatures, some plastics decompose or oxidize, producing low molecular weight substances that can be toxic. Another problem is related to the ingestion of nano, micro, or macro plastics by animals. Thousands of plastic bags are ingested by animals annually. A study of blue petrel chicks on South Africa found that $90 \%$ of them had plastic in their stomachs [20]. These facts contribute to a higher perception in society about the adverse effects of plastics in the oceans/seas. In this sense, measures have been adopted to reduce plastic consumption. China has restricted the use of plastic bags in retail since 2008 and a similar policy was implemented in Malaysia in 2011, in England in 2015 and in Indonesia in 2016 [39]. In Portugal, the plastic bags to carry groceries and other goods were free before, but presently are only provided against payment, encouraging the utilization of reusable bags, and the customers need to bring their own bags or containers. Moreover, in restaurants are prohibited the use of any plastic disposable utensils [40]. This methodology was implemented in Portugal some years ago as a preparatory way for the limitations that the European Union would demand following the regulations approved in 2019, according to which there would be a measurable reduction in the consumption of single-use plastic products in the EU until 2026 [41]. In Portugal, the decrease in the use of disposable plastics in the restoration was expected to start in 2020, before the deadlines established by the European directive. However, due to the Covid-19 pandemic, the measure was postponed. Decree-Law No. 22-A/2021 [42] "is postponed to 1 July 2021 the obligation of catering and beverage service providers to adapt to the provisions of Law no. 76/2019" [43], which determines "the non-use and non-availability of single-use plastic tableware, referring to "activities in the restaurant and/or beverage sector and in the retail trade". As an alternative to disposable plastic, the law defines that "reusable utensils must be used, or, alternatively, utensils made of biodegradable material". Uganda and South Africa have also banned single-use plastic bags. Other countries such as Kenya are considering implementing taxes on plastic bags, or even banning their use [20]. In the current study, $81 \%$ of the interviewees committed to avoiding plastic utensils and to reduce their use of plastic bags. The specific recycling rate for plastic packaging in Portugal reached $44 \%$ in 2018, surpassing the European targets, which stood at $22.5 \%$. The collection of these packages, which are mostly placed in the yellow recycling bin, totalled 72,000 tons in 2018. In the first half of 2019, there was a $5 \%$ increase in the amount of plastic 
packaging waste sent for recycling. During this period, around 30 thousand tons of plastic were collected in the yellow recycling bin [44]. According to the Portuguese organism for recycling Sociedade Ponto Verde (Green Point society), plastic will continue to be part of the consumption cycle, so it is important that all agents have an active contribution in terms of the circularity, sustainability and recyclability of this material. Hence, their compromise is to promote development, knowledge and innovation, investing in valuing and promoting gains from an economic, environmental and positive reputation point of view of a brand, product or company. It is envisaged that Portugal will continue to meet the targets set by the European Union, which stand at 50\% in 2025 and 55\% in 2030 . It is important to emphasize that this requires a joint commitment from all of society, including the citizens, the Government, national and local entities, the industry and the academic community [44].

Six months after implementing the charge for plastic bags in England, it was verified that the number of disposable plastic bags used dropped by more than $85 \%$, around 500 million units. Likewise, there was an increase in the awareness of the environmental impact of household plastic waste and the population's support for the issue [24]. Studies carried out reveal that the reduction policy is effective, instigating the consumer to avoid the use of plastic bags across $52.3 \%$ a year [39]. In the current survey, the majority of participants admit to generating one bag of plastic waste per week, or two to five, which represents a great volume of residues.

A survey on marine pollution carried out in Greece by Gkargkavouzi et al. [37] indicated that, in general, respondents showed positive attitudes and a moderate knowledge about the theme of marine pollution and that they value the marine environment due to the ecosystem services provided. Among the main threats identified, garbage and industries were considered the most important, followed by fishing and agriculture. A study carried out in Italy by Forleo and Romagnoli [38] identified a low involvement of people regarding changes in their purchasing behavior to reduce the amount of plastic packaging. When the people were asked if, in the period of six months before the questionnaire was applied, they had adopted purchasing choices aimed at preventing the use of plastic waste, only $16 \%$ stated that it reduced a lot, and 24\% slightly reduced the purchase. Changing plastic consumption habits has not been an easy task, as it directly depends on the change in the way individuals consume [38]. This could also be verified by the present survey, in which the participants tended to think about the negative impact of the plastic package on the environment. Therefore, the willingness to adopt plastic waste reduction should be strengthened and stimulated, especially among those individuals who are not at all committed or are not often aware of their purchasing and waste behavior. Because of this, research has been carried out to investigate bioplastics, which are polymers from renewable and/or biodegradable resources [45-48]. Degradable biopolymers are an alternative to traditional plastics, especially when recycling is not economically viable, or when the environmental impact must be minimized [49]. Bioplastics can be defined as plastics based on renewable resources, or plastics that are biodegradable and/or compostable. The use of bioplastics as food packaging materials has limitations, such as higher prices compared to conventional plastics and concerns about availability as well as land for its production [50].

Consumers are increasingly concerned about the safety offered by the products which they consume, such as food, water, health-related products such as medicines and other goods used in everyday life [20]. Lavelle-Hill et al. [24] verified that people more concerned with environmental issues are currently younger, female, have more money and a higher education. They found that young adults are more concerned with the environment, but older adults adopt more pro-environmental behaviors. Therefore, specific actions such as purchasing plastic bags may be less motivated by environmental factors and more by economic ones [24]. Nevertheless, this ecological conscientiousness may help increase the adoption of alternative biodegradable materials similar to plastics and bioplastics, many of them obtained from industrial agro-food wastes, as a replacement of traditional plastic materials [14,51]. Social awareness, education and public pressure play key roles in shaping 
and encouraging consumer behavioral changes towards a more environmentally friendly responsibility. Nevertheless, correct habits involve more than just motivation, but also self-discipline and a belief in the positive impact of behavior change [24].

\section{Conclusions}

This work investigates the habits related to food packaging in a sample of Portuguese citizens and their knowledge and concerns about the use of plastics. Regarding research question 1 (RQ1), it was observed that people are more aware of the environmental issues, with $89 \%$ confirming they think about the negative impact of plastic packages. Regarding this, the main concern relates to the impact on seas/oceans (maximum score attributed by 344 participants).

Concerning the RQ2, it was concluded that consumers have a conscience that recycling is a means to reduce environmental pollution and promote the sustainability of the packaging chain. In the same way, they are getting more informed and having a better attitude towards it, with $87 \%$ separating plastic materials for recycling. Most of the interviewees had concerns about the use of plastic packaging, and 55\% are trying to change their habits so as to avoid the use of plastics in this context. Additionally, they know how to separate waste types so that they can be efficiently recycled and have been doing this where possible.

Regarding RQ3, it was concluded that participants know very well about aspects such as the lower environmental impact of recycled materials or the way materials are handled for recycling, but are less informed about the Portuguese effectiveness in meeting recycling targets.

Concerning RQ4, it was concluded that there are significant differences between women and men for the thought about the impact of plastic at the moment of purchase, for separating residues to recycle, for the reduction in plastic bags' usage, as well as for the perception of the negative impact of plastics on the environment. Differences between groups for other sociodemographic variables were, in general, not significant.

In this way, it is expected that society will increasingly move towards sustainable habits, questioning its actions and the impact they have on the environment. To measure this evolution, this study and other related studies might be implemented as a followup strategy (through longitudinal studies) to evaluate the real impact of the legislation presently available to minimize the use of plastics. It might also be important to replicate this study in other countries and compare results.

Author Contributions: Conceptualization, R.P.F.G.; methodology, R.P.F.G.; software, R.P.F.G.; validation, R.P.F.G.; formal analysis, R.P.F.G.; investigation, R.C., L.P.C.-L. and R.P.F.G.; resources, L.P.C.-L. and R.P.F.G.; data curation, R.P.F.G.; writing-original draft preparation, M.W.M., L.P.C.-L. and R.P.F.G.; writing-review and editing, L.P.C.-L. and R.P.F.G.; visualization, R.P.F.G.; supervision, R.P.F.G.; project administration, R.P.F.G.; funding acquisition, L.P.C.-L. and R.P.F.G. All authors have read and agreed to the published version of the manuscript.

Funding: This research was funded by FCT—Foundation for Science and Technology, I.P., Portugal, within the scope of the project Ref. UIDB/00681/2020. The APC was funded by FCT-Ref. UIDB/00681/2020.

Institutional Review Board Statement: The study was conducted according to the guidelines of the Declaration of Helsinki, and approved by the Ethics Committee of Polytechnic Institute of Viseu (reference 09/SUB/2021).

Informed Consent Statement: Informed consent was obtained from all subjects involved in the study.

Data Availability Statement: The data are available from the author Raquel Guiné, upon request.

Acknowledgments: This work is funded by National Funds through the FCT-Foundation for Science and Technology, I.P., within the scope of the project Ref. UIDB/00681/2020. Furthermore, we would like to thank the CERNAS Research Centre and the Polytechnic Institutes of Viseu and Coimbra for their support.

Conflicts of Interest: The authors declare no conflict of interest. 


\section{References}

1. Sundqvist-Andberg, H.; Åkerman, M. Sustainability governance and contested plastic food packaging-An integrative review. J. Clean. Prod. 2021, 306, 127111. [CrossRef]

2. Landim, A.P.M.; Bernardo, C.O.; Martins, I.B.A.; Francisco, M.R.; Santos, M.B.; De Melo, N.R. Sustentabilidade quanto às embalagens de alimentos no Brasil. Polímeros 2016, 26, 82-92. [CrossRef]

3. Aggarwal, A.; Langowski, H.-C. Packaging functions and their role in technical development of food packaging systems: Functional equivalence in yoghurt packaging. Procedia CIRP 2020, 90, 405-410. [CrossRef]

4. De Souza, L.B.; Moura, A.A.C. Embalagens para alimentos: Tendências e inovações. Hig. Aliment 2017, 5, 25-29.

5. Marsh, K.; Bugusu, B. Food packaging? Roles, materials, and environmental issues. J. Food Sci. 2007, 72, R39-R55. [CrossRef]

6. Farmer, N. 6-Packaging and marketing. In Packaging Technology; Emblem, A., Emblem, H., Eds.; Woodhead Publishing: Cambridge, England, 2012; pp. 87-105.

7. Balzarotti, S.; Maviglia, B.; Biassoni, F.; Ciceri, M.R. Glass Vs. Plastic: Affective judgments of food packages after visual and haptic exploration. Procedia Manuf. 2015, 3, 2251-2258. [CrossRef]

8. Kim, H.J.; Kim, S.J.; An, D.S.; Lee, D.S. Monitoring and modelling of headspace-gas concentration changes for shelf life control of a glass packaged perishable food. LWT Food Sci. Technol. 2013, 55, 685-689. [CrossRef]

9. Vaireanu, D.-I.; Cojocaru, A.; Maior, I.; Ciobotaru, I.-A. Food packaging interactions in metal cans. In Reference Module in Food Science; Elsevier: Amsterdam, The Netherlands, 2018.

10. Pasias, I.N.; Raptopoulou, K.G.; Proestos, C. Migration from metal packaging into food. In Reference Module in Food Science; Elsevier: Amsterdam, The Netherlands, 2018.

11. Sapozhnikova, Y. Non-targeted screening of chemicals migrating from paper-based food packaging by GC-Orbitrap mass spectrometry. Talanta 2021, 226, 122120. [CrossRef]

12. He, Y.; Li, H.; Fei, X.; Peng, L. Carboxymethyl cellulose/cellulose nanocrystals immobilized silver nanoparticles as an effective coating to improve barrier and antibacterial properties of paper for food packaging applications. Carbohydr. Polym. 2020, 252, 117156. [CrossRef]

13. Testa, F.; Di Iorio, V.; Cerri, J.; Pretner, G. Five shades of plastic in food: Which potentially circular packaging solutions are Italian consumers more sensitive to. Resour. Conserv. Recycl. 2021, 173, 105726. [CrossRef]

14. Montoille, L.; Vicencio, C.M.; Fontalba, D.; Ortiz, J.A.; Moreno-Serna, V.; Peponi, L.; Matiacevich, S.; Zapata, P.A. Study of the effect of the addition of plasticizers on the physical properties of biodegradable films based on kefiran for potential application as food packaging. Food Chem. 2021, 360, 129966. [CrossRef]

15. Kwon, C.W.; Chang, P.-S. Influence of alkyl chain length on the action of acetylated monoglycerides as plasticizers for poly (vinyl chloride) food packaging film. Food Packag. Shelf Life 2021, 27, 100619. [CrossRef]

16. Van Hai, L.; Muthoka, R.M.; Panicker, P.S.; Agumba, D.O.; Pham, H.D.; Kim, J. All-biobased transparent-wood: A new approach and its environmental-friendly packaging application. Carbohydr. Polym. 2021, 264, 118012. [CrossRef] [PubMed]

17. Hossain, R.; Tajvidi, M.; Bousfield, D.; Gardner, D.J. Multi-layer oil-resistant food serving containers made using cellulose nanofiber coated wood flour composites. Carbohydr. Polym. 2021, 267, 118221. [CrossRef]

18. Wyrwa, J.; Barska, A. Innovations in the food packaging market: Active packaging. Eur. Food Res. Technol. 2017, 243, 1681-1692. [CrossRef]

19. Jalil, A.; Mian, N.; Rahman, M.K. Using plastic bags and its damaging impact on environment and agriculture: An alternative proposal. Int. J. Learn. Dev. 2013, 3, 1-14. [CrossRef]

20. Bashir, N.H.H. Plastic problem in Africa. Jpn. J. Vet. Res. 2013, 61 (Suppl. 2013), S1-S11.

21. Rodrigues, M.; Abrantes, N.; Gonçalves, F.; Nogueira, H.S.; Marques, J.; Gonçalves, A.M. Impacts of plastic products used in daily life on the environment and human health: What is known? Environ. Toxicol. Pharmacol. 2019, 72, 103239. [CrossRef]

22. Henningsson, S.; Hyde, K.; Smith, A.; Campbell, M. The value of resource efficiency in the food industry: A waste minimisation project in East Anglia, UK. J. Clean. Prod. 2004, 12, 505-512. [CrossRef]

23. Forlin, F.J.; Faria, J.D.A.F. Considerações sobre a reciclagem de embalagens plásticas. Polímeros 2002, 12, 1-10. [CrossRef]

24. Lavelle-Hill, R.; Goulding, J.; Smith, G.; Clarke, D.D.; Bibby, P.A. Psychological and demographic predictors of plastic bag consumption in transaction data. J. Environ. Psychol. 2020, 72, 101473. [CrossRef]

25. Adam, I.; Walker, T.R.; Clayton, C.A.; Bezerra, J.C. Attitudinal and behavioural segments on single-use plastics in Ghana: Implications for reducing marine plastic pollution. Environ. Chall. 2021, 4, 100185. [CrossRef]

26. Walker, T.R.; McGuinty, E.; Charlebois, S.; Music, J. Single-use plastic packaging in the Canadian food industry: Consumer behavior and perceptions. Humanit. Soc. Sci. Commun. 2021, 8, 80. [CrossRef]

27. Guiné, R.P.F.; Florença, S.G.; Moya, K.V.; Anjos, O. Edible flowers, old tradition or new gastronomic trend: A first look at consumption in portugal versus Costa Rica. Foods 2020, 9, 977. [CrossRef]

28. Guiné, R.P.F.; Florença, S.G.; Barroca, M.J.; Anjos, O. The link between the consumer and the innovations in food product development. Foods 2020, 9, 1317. [CrossRef]

29. Triola, M.F.; Flores, V.R.L.F. Instrodução ÀEstatística, 12th ed.; LTC: Rio de Janeiro, Brasil, 2017.

30. Levin, J.; Fox, J.A. Estatística Para Ciências Humanas, 9th ed.; Pearson: Rio de Janeiro, Brasil, 2004.

31. Fundação Francisco Manuel dos Santos: PORDATA-Base de Dados Portugal Contemporâneo. Available online: https://www. pordata.pt/Home (accessed on 10 December 2020). 
32. Cochran, W.G. Sampling Techniques, 3rd ed.; John Wiley \& Sons: New York, NY, USA, 1977.

33. Levine, D.M.; Stephan, D.F.; Krehbiel, T.C.; Berenson, M.L. Estatistica Teoria E Aplicacoes Usando O Microsoft Excel Em Portugues, 5th ed.; LTC: Rio de Janeiro, Brasil, 2008.

34. Florença, S.; Correia, P.; Costa, C.; Guiné, R. Edible insects: Preliminary study about perceptions, attitudes, and knowledge on a sample of Portuguese citizens. Foods 2021, 10, 709. [CrossRef] [PubMed]

35. Witten, R.; Witte, J. Statistics, 9th ed.; Wiley: Hoboken, NJ, USA, 2009.

36. Guiné, R.; Bartkiene, E.; Florença, S.; Djekić, I.; Bizjak, M.; Tarcea, M.; Leal, M.; Ferreira, V.; Rumbak, I.; Orfanos, P.; et al. Environmental issues as drivers for food choice: Study from a multinational framework. Sustainability 2021, 13, 2869. [CrossRef]

37. Gkargkavouzi, A.; Paraskevopoulos, S.; Matsiori, S. Public perceptions of the marine environment and behavioral intentions to preserve it: The case of three coastal cities in Greece. Mar. Policy 2019, 111, 103727. [CrossRef]

38. Forleo, M.; Romagnoli, L. Marine plastic litter: Public perceptions and opinions in Italy. Mar. Pollut. Bull. 2021, 165, 112160. [CrossRef]

39. Putri, N.K. Local concern on plastic bag charge in indonesia: Do we really care? In Proceedings of the 1st International Conference Postgraduate School Universitas Airlangga: “Implementation of Climate Change Agreement to Meet Sustainable Development Goals" (ICPSUAS 2017), Surabaya, Indonesia, 1-2 August 2017; Atlantis Press: Almere, The Netherlands, 2017 ; pp. 326-329.

40. Conselho Ministros Portuguese Law. Decreto-Lei n.o 102-D/2020-Aprova o regime geral Da gestão de resíduos, o regime jurídico Da deposição de resíduos em aterro e altera o regime Da gestão de fluxos específicos de resíduos, transpondo as diretivas (UE) 2018/849, 2018/850, 2018/851 e 2018/852. Diário Rep. 2020, 25, 269.

41. The European Parliament; The Council of the European Union. EU Directive (EU) 2019/904 of the European Parliament and of the Council of 5 June 2019 on the Reduction of the Impact of Certain Plastic Products on the Environment [EN]. Off. J. Eur. Union 2019, 155, 1-19.

42. Presidência do Conselho de Ministros. Decreto-Lei n. ${ }^{\circ}$ 22-A/2021 de 17 de Março-Prorroga Prazos e Estabelece Medidas Excecionais e Temporárias No Âmbito Da Pandemia Da Doença COVID-19. Diário Repúb. 2021, 53, $2-8$.

43. Assembleia da República. Lei n. ${ }^{\circ}$ 76/2019 de 2 de Setembro-Determina a Não Utilização e Não Disponibilização de Louça de Plástico de Utilização Única Nas Atividades Do Setor de Restauração e/Ou Bebidas e No Comércio a Retalho. Diário Repúb. 2019, 167, 31-34.

44. SPV Embalagens de Plástico Cumprem Metas de Reciclagem; Sociedade Ponto Verde: Lisboa, Portugal, 2020.

45. Lim, C.; Yusoff, S.; Ng, C.; Lim, P.; Ching, Y. Bioplastic made from seaweed polysaccharides with green production methods. J. Environ. Chem. Eng. 2021, 9, 105895. [CrossRef]

46. García-Depraect, O.; Bordel, S.; Lebrero, R.; Santos-Beneit, F.; Börner, R.A.; Börner, T.; Muñoz, R. Inspired by nature: Microbial production, degradation and valorization of biodegradable bioplastics for life-cycle-engineered products. Biotechnol. Adv. 2021, 107772, in press. [CrossRef] [PubMed]

47. Aversa, C.; Barletta, M.; Gisario, A.; Pizzi, E.; Prati, R.; Vesco, S. Design, manufacturing and preliminary assessment of the suitability of bioplastic bottles for wine packaging. Polym. Test. 2021, 100, 107227. [CrossRef]

48. Nigam, S.; Das, A.K.; Patidar, M.K. Valorization of Parthenium hysterophorus weed for cellulose extraction and its application for bioplastic preparation. J. Environ. Chem. Eng. 2021, 9, 105424. [CrossRef]

49. Schwark, F. Influence factors for scenario analysis for new environmental technologies-The case for biopolymer technology. J. Clean. Prod. 2009, 17, 644-652. [CrossRef]

50. Peelman, N.; Ragaert, P.; De Meulenaer, B.; Adons, D.; Peeters, R.; Cardon, L.; Van Impe, F.; Devlieghere, F. Application of bioplastics for food packaging. Trends Food Sci. Technol. 2013, 32, 128-141. [CrossRef]

51. Jõgi, K.; Bhat, R. Valorization of food processing wastes and by-products for bioplastic production. Sustain. Chem. Pharm. 2020, 18, 100326. [CrossRef] 